\title{
Shop-hop till you drop! The effect of the image gap on spillover patronage within retail agglomerations
}

\author{
Sheng Wei ${ }^{\mathrm{a}}$, Hong Huo ${ }^{\mathrm{a}}$, Ming Xu ${ }^{\mathrm{b}}$, Djavlonbek Kadirov ${ }^{\mathrm{c}}$, Kim-Shyan Fam ${ }^{\mathrm{a}, \mathrm{d},}$ \\ ${ }^{a}$ School of Management, Harbin University of Commerce, 1 Xuehai Street, Harbin, 150028, China \\ ${ }^{\mathrm{b}}$ Yatai School of Business Administration, University of Finance and Economics, 699 Jingyue Street, Changchun, 130117, China \\ ${ }^{c}$ School of Marketing and International Business, Victoria University of Wellington, New Zealand \\ ${ }^{\mathrm{d}}$ Department of Marketing, Romanian American University, Bucharest, Romania
}

\section{A R T I C L E I N F O}

\section{吉林大学博士学位论文}

\section{Keywords:}

Spillover effects

Spillover shopping

Shop patronage

Spillover patronage

Retail agglomerations

Anchor shops

Shopping mall

\begin{abstract}
A B S T R A C T :
Despite strong evidence for the existence of spillover effects in consumer patronage between anchor stores and other less dominant stores in shopping malls, research on spillover patronage antecedents and its underlying formation mechanisms appears to be sparse. The current study explores the effect of the difference between perceived store image for anchor versus non-anchor stores on cross-shop consumer behavior drawing from theories of spillover shopping and retail patronage. Employing a questionnaire survey and laboratory experiments to obtain data on shopping experiences, this study shows that the smaller the image gap between an anchor store and non-anchor stores, the greater the likelihood of non-anchor store patronage by customers originally attracted to the anchor store. This study also finds that when customers attracted by the anchor store experience greater self-image congruity with non-anchor stores, the extent of spillover patronage increases, while this happens irrespective of whether they engage or do not engage in purchase in the anchor store. This study provides a viable theoretical basis for facilitating decision-making in both planning and design of effective retail agglomerations.
\end{abstract}

\section{Introduction}

This research aims to explore antecedents of spillover shopping as well its potential formation mechanisms and boundary conditions within retail agglomerations containing big-box anchor stores and other satellite retail shops. Understanding spillover shopping patterns is of paramount importance (Ailawadi et al., 2010; Arcidiacono et al., 2019; Artz and Stone, 2006; Chung et al., 2021; Daunfeldt et al., 2019; Merriman et al., 2012), since the nature and dynamics of spillover shopping affects not only how retail agglomerations are planned (Teller and Schnedlitz, 2012), but also the effectiveness of local policies and subsidies to attract big-box retailers (Daunfeldt et al., 2019; Greenstone et al., 2010), local growth and employment (Daunfeldt et al., 2019), and economies of agglomeration (Chung and Kalnins, 2001; Greenstone et al., 2010; Teller and Schnedlitz, 2012). Although most researchers tend to agree that spillover shopping as a phenomenon exists, the debate on the nature of its effects is still far from being finalised with some researchers offering evidence for mixed effects (Artz and Stone, 2006;
Chung et al., 2021; Paruchuri et al., 2009), while others claiming positive spillover effects (Basker, 2005; Sobel and Dean, 2008; Shoag and Veuger, 2018), whereas a majority of researchers offering evidence of negative spillover effects (Ailawadi et al., 2010; Arcidiacono et al., 2019; Artz and Stone, 2006; Haltiwanger et al., 2010; Merriman et al., 2012; Stone, 1997). Although consumers' psychographic traits and individual perceptions play a significant role in how spillover shopping patterns are shaped in any given locality, most of the existing research does not consider perceptual parameters of shopping spillover. Rather, the existing research estimates spillover effects based on foot traffic (Chung et al., 2021), shop entries and exits (Paruchuri et al., 2009; Merriman et al., 2012), jobs (Basker, 2005), prices (Basker, 2007), the number of small businesses and establishments (Haltiwanger et al., 2010; Sobel and Dean, 2008; Shoag and Veuger, 2018; Stone, 1997), store merchandise movement data (Ailawadi et al., 2010), and retail revenues and sales (Arcidiacono et al., 2019; Artz and Stone, 2006). Hence, additional avenues still exist for further exploring shopping spillover effects based on consumer perceptions and psychographics.

\footnotetext{
* Corresponding author. School of Management, Harbin University of Commerce, 1 Xuehai Street, Harbin, 150028, China.

E-mail addresses: victory-wei@163.com (S. Wei), huohong1963@126.com (H. Huo), xuming@jlufe.edu.cn (M. Xu), djavlonbek.kadirov@vuw.ac.nz (D. Kadirov), kimfam88@gmail.com (K.-S. Fam).
} 
It is known that retail agglomerations offer consumers increased possibilities to engage in cross-shop product comparisons as well as multi-purpose shopping trips (Arentze et al., 2005; Teller and Elms, 2012). Within a typical shopping mall, a planned retail agglomeration (Teller and Thomson, 2012), stores are organized within a bounded locality through deliberate design and planning, which entail substantial benefits to these stores from consumer shop-hopping giving rise to economies of agglomeration (Teller and Schnedlitz, 2012). Hence, the most common source of agglomeration benefits is a spillover of consumer demand arising from concentration of multiple shops in a single location. Adopting the perspective of the shopper, we label this type of externality as customer spillover patronage (Gatzlaff et al., 1994). Reflecting the psycho-social aspect of spillover shopping underscored by individual consumers' perceptions and experiences, the concept of spillover patronage refers to a willingness of the customer of an anchor store to scout adjacent areas and patronize less-dominant stores in nearby locations, thus enabling these stores to obtain additional customers (Wei and Hou, 2016; Wei and Wu, 2013). That is to say that we imagine positive spillover patronage, whereby the entry or existence of an anchor store might lead to an increase of customer traffic in a non-anchor store located nearby in the long-term (Chung et al., 2021), thus reflecting the consumer's additional serendipitous, unintended patronage intent. The main assumption we maintain in this research is that the deeper the willingness to effect spillover patronage at an individual level, the greater the extent of total benefits accrued to the retail agglomeration as a whole. Therefore, within the limited boundaries of a shopping mall, improving the intent of spillover patronage at an individual level can be seen as an effective means to enhance the shopping mall's effectiveness.

The following research questions guide the current study. What are the factors that affect spillover patronage? What mechanisms underlie spillover patronage effects and what conditions characterize spillover patronage and its likelihood of occurrence? In the existing literature, there are no clear answers or viable explanations to these specific questions. As mentioned earlier, the spillover shopping literature focuses on non-psychometric factors, whereas another stream of research examines the effect of store image on customer patronage within a single store (Roy and Ghosh, 2013; Burlison and Oe, 2018). In the latter group of research, customer store patronage is explained via self-image congruence theory combined with customers' self/store image perceptions (Hosany and Martin, 2012; Sung and Huddleston, 2018). These causal relationships involving store/self-image congruence and patronage pertain to customer behavior in a single store, but these do not directly explain why customers cross-patronize different stores. In addition, store image is considered to be one of the important factors (Baker et al., 1994; Wei and Wu, 2013; Diallo and Cliquet, 2016) which might significantly affect spillover patronage (Pan and Zinkhan, 2006; Belwal and Belwal, 2017; Burlison and Oe, 2018; Wange, 2012).

This research contributes to the existing body of knowledge in the following ways. First, it explores the experiential aspect of spillover shopping (Chung et al., 2021; Daunfeldt et al., 2019), which is re-conceptualized as spillover patronage (Wei and Hou, 2016). Second, it extends the existing research on store patronage into the context of cross-patronization among multiple stores within a single shopping mall (Roy and Ghosh, 2013; Burlison and Oe, 2018). Third, it provides evidence that the perceived image gap between the anchor store and respective non-anchor shops represents a significant antecedent of spillover patronage, whereas multiple self-congruity mediates the effect of the image gap on spillover patronage. Moreover, this research shows that the purchase incidence in an anchor store moderates the effect of the image gap on spillover patronage.

\section{Theoretical background}

\subsection{From general spillover shopping to personal spillover patronage}

Spillover shopping is a specific type of brand externality (Padela et al., 2020) related to the symbolism of brand images within broader marketing systems (Kadirov and Varey, 2011; Conejo and Wooliscroft, 2015). Padela et al. (2020) review mostly negative externalities pertaining the symbolic nature of brands which allows them to develop an insightful typology of brand effects. Moreover, the existing literature explores the following types of spillover effects: advertising spillover between parent brand and sub-brand within the same brand family (Balachander and Ghose, 2003), spillover of one attribute to another (Ahluwalia et al., 2001), and spillover among advertisements of different brands (Erdem and Sum, 2002). In addition, research on the spillover effect of brand scandals is particularly extensive (John et al., 1998; Lei et al., 2008). Research shows that sub-brands generally do not weaken beliefs about parent brands (John et al., 1998), whereas the strength and direction of association between brands influence the extent of brand scandal spillover (Lei et al., 2008). In addition, research on spillover in brand scandals appears to be inconclusive: a brand in crisis might entail positive spillover effects thus indirectly affecting competitors (Reilly and Hoffer, 1983), negative spillover effects (Roehm and Tybout, 2006), or both positive and negative spillover effects (Dahlén and Lange, 2006). Another comparable concept to spillover shopping is communicative spillover. In contrast to shopping spillover, communicative spillover is purely informational. It "refers to the extent to which a message influences beliefs related to attributes that are not contained in the message" (Ahluwalia et al., 2001, p.458). Research on communicative spillover effects provide a good theoretical basis for conceptualizing spillover patronage. Communicative spillover between brands is closely related to spillover patronage because of similarities between retail brands (i.e. stores) and brands in general. To sum up, spillover effect between brands may depend on different factors including the focal brand's characteristics, the recipient brand's characteristics, and the extent to which these brands are perceived to be similar (Ahluwalia et al., 2001).

Research on spillover effects in consumers' shopping behavior mostly deals with the impact of the big-box retailers' entry on incumbent smaller retailers (Ailawadi et al., 2010; Arcidiacono et al., 2019; Artz and Stone, 2006; Chung et al., 2021; Daunfeldt et al., 2019; Merriman et al., 2012). In general, research indicates that spillover shopping effects are variable in nature depending on consumer preferences, product category, spatial/location factors, and temporal factors. Big box retailers with strong brand image and recognition, such as Walmart and IKEA, tend to create significant spillover shopping effects, both positive and negative, through permanently altering consumer preferences (Artz and Stone, 2006; Daunfeldt et al., 2019; Haltiwanger et al., 2010; Merriman et al., 2012). A number of researchers use aggregate sales data to pinpoint the nature of spillover effects. For instance, Artz and Stone (2006) studied the spillover effects of Walmart's entry on the sales of other shops in smaller towns and they found that the total per capita sales of services, restaurants, and apparel stores increased post-entry, while the sales of food and buildings materials declined. These findings supported Stone's (1997) earlier results. In the same vein, Arcidiacono et al. (2019) show a significant negative spillover effect of Walmart's entry on the revenues of other incumbent supermarkets. In the same vein, Chung et al. (2021) show that both positive and negative spillover effects of a mega-shopping centre on smaller retail shops may vary depending on spatial location, temporal dynamics (short-term versus long-term), and across retail types. The dominant shop tends to have negative short-term effect on general merchandise retailers, while its short-run effect on bars/restaurants proved to be positive. However, the authors find that in the long-run the negative effect is transformed into a positive effect for all types of retailers (Chung et al., 2021).

The extant research employs different methods to pinpoint spillover 
shopping. Most of these methods rely on aggregated or retailer specific data including foot traffic (Chung et al., 2021), sales and revenues (Artz and Stone, 2006; Daunfeldt et al., 2019), new shop entries and exits (Paruchuri et al., 2009; Merriman et al., 2012), jobs and prices (Basker, 2005, 2007), the number of small businesses and establishments (Haltiwanger et al., 2010; Sobel and Dean, 2008; Shoag and Veuger, 2018; Stone, 1997) and store merchandise movement data (Ailawadi et al., 2010). However, what is missing is the analysis that looks into consumers' personal experiences and perceptions related to spillover shopping. Consumers shop browsing behavior (Reynolds et al., 2012), store image formation (Pan and Zinkhan, 2006; Belwal and Belwal, 2017; Burlison and Oe, 2018) underlie the consumer level aspects of shopping spillover. There appears to be the need to conceptualize the psycho-social aspect of spillover shopping by using a slightly different label. Hence, we introduce the concept of spillover patronage. Through highlighting individual consumers' perceptions and experiences, the concept of spillover patronage refers to a psychological willingness, intent, process and tendency of the customer of an anchor store to scout adjacent areas, browse and patronize less-dominant stores in nearby locations, thus enabling these stores to obtain additional customers (Wei and Hou, 2016; Wei and Wu, 2013).

\subsection{Theoretical underpinnings of spillover patronage}

Spillover patronage, as a focal phenomenon, can be explained based on the following theories: spreading activation theory, accessibilitydiagnosticity theory and assimilation-contrast theory. Spreading activation theory sees memory as a network of nodes interconnected by links, where a series of nodes can induce associations with other nodes (Collins and Loftus, 1975). When two nodes in the consumer's mind are strongly connected, one can activate the other (Collins and Loftus, 1975). Shoppers store information about stores in their memory, while the stores they have visited would not be completely erased in their memories. According to spreading activation theory, when a store in memory is connected with other stores appearing in front of the customer, the information cues of the store in memory activates a perception of the current store, thus linking potential patronage behavior of these two stores. Furthermore, accessibility-diagnosticity model (Feldman and Lynch, 1988) is also used to explain spillover patronage effects (e.g. Janakiraman et al., 2009; Wang et al., 2012). This model mainly includes two elements. The first element is perceptual diagnostic ability of former judgment for latter judgment, where the correctness of recognition in the latter judgment depends on the former judgment. This element explains how two assessments relate to each other according to consumer suggestion theory. The second element is accessibility, which means that what matters is not only accessibility of the previous judgment in memory, but also the accessibility of an alternative input to the latter judgment. Stores in a shopping mall tend to be interrelated (e.g. adjacent locations, similar merchandise, similar atmosphere, etc.). If relevant cues of store A are diagnostic about store B, then shoppers may infer relevant characteristics of store B from relevant cues about store A, which can potentially bring about spillover patronage. Moreover, assimilation-contrast theory holds that people unconsciously compare similar things around them for the purpose of evaluation or decision. An assimilation-contrast process produces assimilation effect involving an expected convergence of an object and standards, as well as the contrast effect related to deviation between the object and the corresponding standards. If shoppers pay attention to similarities among stores, similar cues among stores may become activated, which would eventually lead to assimilation effect. On the contrary, if people pay more attention to differences among stores, contradictory cues among stores would be activated, which would eventually lead to contrast effect. These three theories underscore a common variable, that is, image differences between the anchor store and other stores. It can be seen that both theoretical deduction and the existing conclusions lead us to believe that the image difference might be an important antecedent in explaining spillover patronage. In summary, we note that the existing studies explain spillover shopping either at the level of individual store or retail agglomeration, while overlooking individual perceptions based spillover patronage.

Spillover patronage is related to the concept of retail agglomeration patronage. The latter concept involves the structure of retail agglomeration image and its influence on shoppers' attitudes and behaviors (Nevin and Houston, 1980; Chebat et al., 2010). It also comprises of theory of self-congruence as it relates to retail agglomeration patronage (Ha and Im, 2012). Neither the concept of store patronage nor that of retail agglomeration patronage, taken individually, take into account the existence of retail demand externalities. These concepts tend to overlook the incidence of customer spillover patronage, where shops could deliberately adopt corresponding marketing strategies to increase the number of such customers. Tamura Masanori (2014) is recognized as a pioneer of investigations on spillover patronage. He concludes that the drawing power of a retail agglomeration depends on anchor stores, that is to say, the customers attracted by anchor stores have a spillover impact on specialty stores (Tamura Masanori, 2014). Wang and Zhang (2012) conducted an exploratory research on the influence factors of spillover patronage. They conclude that the effect of spillover patronage indeed exists between stores and that spillover customers flow from anchor stores to specialty stores. Nevertheless, this existing literature fails to provide a reasonable explanation for the formation mechanisms of spillover patronage.

\section{Conceptual model and hypotheses}

Based on the three theories discussed in the previous section, we offer a conceptual model of spillover patronage depicted in Fig. 1. The conceptual model exhibits the antecedents and moderators explaining spillover patronage in the context of retail agglomerations.

We introduce store image gap as the main antecedent in the model. The effect of this antecedent can be justified through the following arguments. In retail research, Martineau (1958) introduced the concept of store image. A number of scholars pursued the study of store image taking different perspectives (Baker et al., 1994; Wei and Wu, 2013; Diallo and Cliquet, 2016). These studies showed that store image had an effect on customers' store choice and patronage intention (Pan and Zinkhan, 2006; Belwal and Belwal, 2017; Burlison and Oe, 2018). Shoppers who patronize anchor stores retain some information about the anchor store in their mind, which means that information cues relating to the anchor store would be accessible. Research shows that simply browsing a store creates deep psychological effects such as sensory stimulation, self-gratification, and learning (Reynolds et al., 2012; Westbrook and Black, 1985). Whether the shopper will use the suggestive information of the anchor store for the decision of patronizing the non-anchor store also depends on the diagnosability of the information. If the shopper judges the acceptable similarity or causality between the two stores according to his/her knowledge background, the information cue will be diagnosable, and then it turns into the cue that influences decision-making (Wang et al., 2012). Therefore, perceived similarity between anchor stores and non-anchor stores becomes the precondition of diagnostic information cues. When the image of the two stores are similar, i.e. the image gap is small, the information cues of the anchor

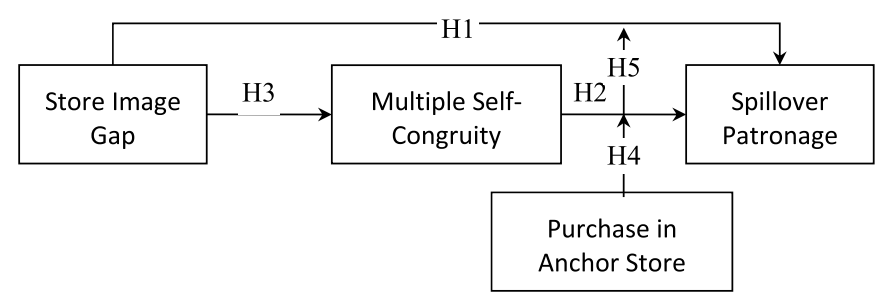

Fig. 1. Conceptual model. 
store will have accessibility and diagnosticity at the same time. Based on the theory of spreading activation, the anchor store cues in the shopper's mind can activate the cognition of non-anchor stores, and then produce spillover patronage. Therefore, we propose that:

H1. The smaller the extent of perceived image gap between an anchor store and a non-anchor store, the greater the extent of spillover patronage.

In the model, the second antecedent is multiple self-congruity. Since early times, the self-concept was introduced as a factor explaining patronage behavior (Dolich, 1969). Self-image congruence theory posits that consumers will match store image with their own self-image, while experiencing store-image/self-image congruence (Sirgy, 1982; Chebat et al., 2006). Self-image congruence can affect store preference (Chebat et al., 2006), as well as store satisfaction and loyalty (Hosany and Martin, 2012). If the shopper experiences greater self-image congruence with an anchor store, they may also experience greater self-image congruence of non-anchor stores, because the real self-image of individuals is relatively stable (Onkvisit and Shaw, 1987). This might make three images, namely the anchor store's image, the non-anchor store's image and the shopper's self-image, reach a congruence. We call it multiple self-congruity. According to self-image congruence theory, customers attracted by the anchor store experience higher self-image congruence when their self-image matching the typical customer image of anchor stores. At the same time, if they experience higher self-image congruence with the non-anchor store, then they are likely to patronize this non-anchor store (Hosany and Martin, 2012; Sung and Huddleston, 2018), which will bring about spillover patronage. Therefore, we propose that:

H2. The greater the extent multiple self-congruity, the greater the extent of spillover patronage.

Any discrepancy between the images of anchor stores and nonanchor stores hinders anchor/non-anchor self-image congruence, especially, when one considers the stability of the shoppers' self-image (Onkvisit and Shaw, 1987). Consumers' self -identification with a retailer can be both cognitive and affective (Wolter and Cronin, 2016; Wolter et al., 2017). A greater image gap might lead to a strong negative affective reaction in terms of a customer's identification with several retailers (Wolter and Cronin, 2016). According to assimilation-contrast theory (De Bruyn and Prokopec, 2017; Vogel et al., 2020), the additional information received by the consumer should be congruent with the his/her established beliefs to be easily assimilated. If the gap between the new information and the established perceptions is significantly large, the new information will be rejected. Extending this to the retailing context, we argue that when the images of anchor stores and non-anchor stores are similar, as long as the shopper experiences self-image congruence with both anchor stores and non-anchor stores, assimilation effect will occur, and then the shopper will experience multiple self-congruity. So, the smaller image gap makes it easier for shoppers to form combined anchor/non-anchor self-image congruence.

H3. The relatively smaller image gap leads a greater extent of multiple self-congruity.

The incident of a completed purchase in a shop has a significant effect on consumers subsequent shopping and browsing behaviors (Reynolds et al., 2012). Reynolds et al. find that customers who make a purchase tend to have greater repatronage intention and greater repatronage anticipation compared to other consumers who do not make a purchase. We assume that such repatronage intentions will spill over to other local retailers if multiple-self congruity level is high. Moreover, consumers are more likely to value anonymous browsing afforded by big-box retailers (Noble et al., 2006). Anonymously browsing and purchasing in anchor store might create deep satisfaction in the customer, who might want to repeat such experiences in similar stores in the vicinity. Hence,

H4. Purchase in anchor store will amplify the positive effect of multiple self-congruity on spillover patronage.

There are two potential outcomes of a completed purchase within an anchor store: experiential and physical. Experientially, a completed purchase might create feelings of satisfaction, enjoyment, and accomplishment (Reynolds et al., 2012; Westbrook and Black, 1985). Physically, the consumer may end carrying heavy or bulky goods after shopping in the anchor store. These two outcomes might hinder further browsing and shopping behavior. Especially, the urge to finalize shopping and leave the shopping centre would be great if the image gap is significantly large. Such hindrance may not be a problem when the image gap is small, since browsing would be considered as a continuation of the same shopping experience. If no purchase occurred, then the consumer's feeling of accomplishment would not exist. In this case, image gap's effect on spillover patronage will be more or less attenuated.

H5. Purchase in anchor store will amplify the negative effect of image gap on spillover patronage.

\section{Study one}

\subsection{Research design}

The main purpose of Study One is to test the effect of store image gap on spillover patronage through intercept interviews in a shopping mall. Store image is measured on the basis of shopper perceptions about the focal anchor store and the adjacent non-anchor stores. The store image construct includes the items derived from Baker et al. (1994). Spillover patronage is measured on the basis of the items proposed by Wang and Zhang (2012). All items are 5-point Likert scales (refer to Table 1).

In order to neutralize a potential order bias, we create two versions of the same questionnaire. Version 1 positions the items relating to anchor store image first, followed by the items relating to non-anchor stores' image. Version 2 reverses the order: it presents the items relating to nonanchor stores' image first, then followed by the items relating to anchor store image. The data is collected from the following areas: a) Wanda Plaza in Changchun City (Version 1) where the focal anchor store was $\mathrm{H} \& \mathrm{M}$ and non-anchor stores were small retailers located close to the anchor store such as Hotwind; b) Wanda Plaza in Changchun City (Version 2) where the anchor stores are Huarun Wanjia Supermarket and Big Player and non-anchor stores were small stores located in proximity to such as Hotwind and Watsons; c) Xintiandi Shopping Center where the anchor stores were Xintiandi Department Store,

Table 1

Results of measurement model for Study 1.

\begin{tabular}{|c|c|c|c|c|c|}
\hline Items & Estimate & $\mathrm{T}$ & AVE & $\mathrm{CR}$ & $\begin{array}{l}\text { Cronbach's } \\
\alpha\end{array}$ \\
\hline Anchor Store Image & & & 0.531 & 0.818 & 0.816 \\
\hline $\begin{array}{l}\text { This store is a pleasant } \\
\text { place to shop. }\end{array}$ & 0.667 & - & & & \\
\hline $\begin{array}{l}\text { The store has a pleasant } \\
\text { atmosphere. }\end{array}$ & 0.799 & 14.957 & & & \\
\hline This store is clean. & 0.759 & 14.481 & & & \\
\hline This store is attractive. & 0.682 & 13.322 & & & \\
\hline $\begin{array}{l}\text { Non-anchor Store } \\
\text { image }\end{array}$ & & & 0.633 & 0.873 & 0.880 \\
\hline $\begin{array}{l}\text { These stores are a } \\
\text { pleasant place to shop. }\end{array}$ & 0.817 & - & & & \\
\hline $\begin{array}{l}\text { These stores have a } \\
\text { pleasant atmosphere. }\end{array}$ & 0.765 & 18.788 & & & \\
\hline These stores are clean. & 0.752 & 18.481 & & & \\
\hline $\begin{array}{l}\text { These stores are } \\
\text { attractive. }\end{array}$ & 0.844 & 21.471 & & & \\
\hline Spillover patronage & & & 0.748 & 0.856 & 0.859 \\
\hline $\begin{array}{l}\text { I patronize these small } \\
\text { stores after coming out } \\
\text { of the anchor store. }\end{array}$ & 0.854 & - & & & \\
\hline I shop in these stores. & 0.876 & 17.618 & & & \\
\hline
\end{tabular}


Carrefour Supermarket, Suning Electrical Appliances and the nonanchor stores located in close proximity such as Watsons and Selected. To make sure that respondents represent individuals who are originally attracted to the anchor store, they were approached in the vicinity of the anchor store, specifically as they came out of the store. Then, as a filter question, they were asked if they specifically came to shop at the anchor store and if they were attracted by this store. If the answers were 'yes', they were invited to complete the questionnaire. In the process, we obtained 260 full questionnaires based on Version 1. Out of them 89 responses were from males (34.2\%) and 171 responses were from females $(65.8 \%)$. Further, we collected 270 responses based on Version 2 questionnaire, where 124 were from males (45.9\%) and 146 were from females (54.1\%). In total, we have collected 530 valid responses.

\subsection{Data analysis}

\subsubsection{Testing the measurement model and calculating store image gap}

We perform confirmatory factor analysis comprising the following constructs: anchor store image, non-anchor store image, and spillover patronage. The analysis shows that the model fits well $\left(\chi^{2}=79.542, \mathrm{df}\right.$ $=27, \mathrm{p}<0.05, \chi^{2} / \mathrm{df}=2.946, \mathrm{GFI}=0.973$, AGFI $=0.944, \mathrm{CFI}=$ 0.981 , RMSEA $=0.061$ ). Based on the cutoff criteria proposed by $\mathrm{Hu}$ and Bentler (1999), most indices appear to be excellent apart from RMSEA which appears to be acceptable (refer to Table 1). Table 1 indicates that the standardized factor loadings of all items are greater than 0.6 , and significant. Also, the reliability and validity measures appear to be satisfactory: AVEs are greater than 0.5 , CRs are greater than 0.7 , and Cronbach's Alphas are greater than 0.7. In addition, we calculate store image gap through averaging the absolute values of differences between the corresponding items of anchor store image and non-anchor store image. The following formula is used:

Store Image Gap $=\frac{\sum_{n=1}^{4} \mid \text { Anchor store image }- \text { Non_anchor store image } \mid}{4}$

We use store image gap as an independent variable and spillover patronage as a dependent variable to perform regression analysis. The results of the analysis are given in Table 2.

Version 1 data show that store image gap has a significant effect on spillover patronage $(\beta=-0.381, p<0.001)$. The same pattern can be seen in Version 2 data as well $(\beta=-0.461, p<0.001)$. The pooled data provides a more consistent result. The negative sign indicates that the smaller the image gap, the greater the extent of spillover patronage. These results provide sufficient evidence in support of $\mathrm{H} 1$.

\section{Study two}

We design a set of 2 (anchor store image: upscale vs downscale) x 2 (non-anchor store image: upscale vs downscale) factorial experiments. In these experiments, both anchor store image and non-anchor store image are manipulated by videos specifically developed for this purpose. In these experiments, the experimental subjects were college students. There were 132 subjects in total: 57 males (43.18\%) and 75 females (56.82\%). After watching videos, the participants were asked to imagine that they came to specifically shop at the anchor store. Then, they answered questions regarding their perception of multiple selfcongruity, spillover patronage and their purchase behavior in the anchor store.

\subsection{Experimental design}

In order to avoid bias caused by the subject's familiarity with the experimental materials, most of the videos were shot in shopping malls and department stores outside the experimental city. A small part of the videos came from the Internet. A total of 56 videos were shot/collected, totaling $114 \mathrm{~min}$. Also, 46 pictures depicting apparel and fashion stores were downloaded from websites such as Nitu. These images were inserted into the videos in the form of animation. The videos were professionally edited by audiovisual experts using Adobe Premiere Pro software.

To pilot test the experimental settings and in order to confirm whether the subjects can satisfactorily complete the questionnaire according to the video content after watching the video, we invited 11 marketing specialists (academics, researchers, practitioners) to watch the videos, and then fill out the pilot questionnaire. They all expressed that they had no difficulty completing the questionnaire after being exposed to the video content. Based on some of their suggestions, several items were further improved.

The video of the anchor store lasts $170 \mathrm{~s}$. It consists of three parts: 1) the shopping mall orientation map and explanation (25s); 2) the description (which manipulates the factors such as self-image congruence of the anchor store, payment ability, time and social settings (20s), and 3) the video of the anchor store (125s), including the general outline of atrium, layout, corridor, stores on both sides of the corridor (45s) and merchandise quality, quantity, display, and models (80s). The video content and structure of upscale anchor stores and downscale anchor stores are kept similar. The video of non-anchor stores lasts $90 \mathrm{~s}$. It consists of two parts: 1) the shopping mall map and the explanation of the location of non-anchor stores (20s), and 2) the video of non-anchor stores (70s) including the path from the anchor store to non-anchor stores (8s), merchandise quality, quantity, display, and models (62s). The video content and structure of upscale non-anchor stores and downscale non-anchor stores are designed to be identical.

The calculation and measurement of store image and spillover patronage was the same as in the previous study. Self-image congruence was measured by the three items from Sirgy et al. (1997). The questionnaire was presented to the subjects in the form of 5-point Likert scales. The incidence of purchase in the anchor store was measured by asking the following question: "Would you have bought anything by the time you have finished shopping in this store?" Store image gap was calculated using the method described in the preceding section.

\subsection{Testing the measurement model for study 2}

We conduct confirmatory factor analysis using AMOS. The model fits well $\left(\chi^{2}=31.02, \mathrm{df}=20, \mathrm{p}=0.055,\left(\chi^{2} / \mathrm{df}=1.551\right.\right.$, GFI $=0.952$, AGFI $=0.892$, CFI $=0.974$, RMSEA $=0.065$, PClose $=0.268)$. The model fit has improved significantly after we have accounted for some covariances between error terms of image gap.

The standard factor loadings of the items are greater than 0.50 and these are significant (see Table $3 a$ ). The CR values of all constructs are greater than 0.70 , while the AVE values of the constructs are greater than 0.50 . The convergent validity of the constructs are assessed by synthesizing the standardized factor loadings, CR values and AVE values (Bagozzi and Yi, 1988). On the basis of these values we confirm the satisfactory reliability for each construct.

Table $3 \mathrm{~b}$ shows that there appears to be no major concern regarding

Table 2

Effect of store image gap on spillover patronage.

\begin{tabular}{|c|c|c|c|c|c|c|}
\hline & Standardized coefficient & $\mathrm{t}$ & sig & $\mathrm{R}^{2}$ & $\mathrm{~F}$ & Freedom \\
\hline Version 1 & -0.381 & -6.609 & .000 & 0.145 & 43.685 & $1 / 258$ \\
\hline Version 2 & -0.461 & -8.510 & .000 & 0.213 & 72.417 & $1 / 268$ \\
\hline Full sample & -0.401 & -10.053 & .000 & 0.161 & 101.058 & $1 / 528$ \\
\hline
\end{tabular}


Table 3a

Confirmatory factor analysis results for Study 2 .

\begin{tabular}{|c|c|c|c|c|c|}
\hline Measuring items & Estimate & $\begin{array}{l}t \\
\text { value }\end{array}$ & AVE & CR & $\begin{array}{l}\text { Cronbach's } \\
\alpha\end{array}$ \\
\hline Store Image Gap & & & 0.519 & 0.811 & 0.785 \\
\hline Image Gap 1 & 0.608 & - & & & \\
\hline Image Gap 2 & 0.787 & 3.910 & & & \\
\hline Image Gap 3 & 0.720 & 3.768 & & & \\
\hline Image Gap 4 & 0.754 & 3.844 & & & \\
\hline Multiple Self-Congruity & & & 0.691 & 0.867 & 0.771 \\
\hline $\begin{array}{l}\text { I am identical to the typical } \\
\text { customers of these stores. }\end{array}$ & 0.765 & - & & & \\
\hline $\begin{array}{l}\text { I'm not at all like any of the } \\
\text { typical customers in } \\
\text { these stores. }\end{array}$ & 0.690 & 4.879 & & & \\
\hline $\begin{array}{l}\text { I feel that my personal } \\
\text { profile is similar to the } \\
\text { typical customers in } \\
\text { these stores. }\end{array}$ & 1.006 & 5.947 & & & \\
\hline Spillover Patronage & & & 0.608 & 0.755 & 0.749 \\
\hline $\begin{array}{l}\text { I patronize these small } \\
\text { stores after coming out of } \\
\text { the anchor store. }\end{array}$ & 0.719 & - & & & \\
\hline I shop in these stores. & 0.836 & 6.536 & & & \\
\hline
\end{tabular}

Table 3b

Correlations between the constructs and the square root of AVE.

\begin{tabular}{|c|c|c|c|}
\hline & $\begin{array}{l}\text { Store Image } \\
\text { Gap }\end{array}$ & $\begin{array}{l}\text { Multiple Self- } \\
\text { congruity }\end{array}$ & $\begin{array}{l}\text { Spillover } \\
\text { patronage }\end{array}$ \\
\hline Store Image Gap & 0.720 & & \\
\hline $\begin{array}{c}\text { Multiple Self- } \\
\text { Congruity }\end{array}$ & -0.108 & 0.831 & \\
\hline Spillover Patronage & $-0.613^{\mathrm{a}}$ & $0.381^{\mathrm{a}}$ & 0.780 \\
\hline
\end{tabular}

${ }^{\text {a }}$ Indicates $\alpha<0.001$.

discriminant validity. Regarding the potential issue of common method bias, we perform Harman single factor analysis. We find that the first component's total variance explained is equal to $38.11 \%$ which is less than the $40 \%$ criterion. Combined with the confirmatory factor analysis results, we conclude that there is no issue of a single source of variance emerging which could have been attributed to the use of a common method.

\subsection{Store image manipulation test}

We use independent samples t-tests to examine the differences between a) upscale anchor store image and downscale anchor store image; b) upscale non-anchor store image and downscale non-anchor store image. The results show that there is a significant difference between upscale anchor store image and downscale anchor store image $\left(\mathrm{M}_{\text {upscale }}\right.$ $\left.=4.181, \mathrm{M}_{\text {downscale }}=2.909, \mathrm{t}=11.728, \mathrm{p}<0.001\right)$. Also, there is a significant difference between upscale non-anchor store image and downscale non-anchor store image $\left(\mathrm{M}_{\text {upscale }}=4.131, \mathrm{M}_{\text {downscale }}=\right.$ 2.577, $\mathrm{t}=14.157, \mathrm{p}<0.001$ ). In addition, we expect no significant differences between upscale (downscale) anchor store image and upscale (downscale) non-anchor store images. The paired sample t-tests showed that there was no significant difference between upscale anchor store image and upscale non-anchor store image $\left(\mathrm{M}_{\text {anchor }}=4.050, \mathrm{M}_{\text {non- }}\right.$ anchor $=4.300, t=-1.789, \mathrm{p}>0.05)$. Also, there was no significant difference between downscale anchor store image and downscale nonanchor store image $\left(\mathrm{M}_{\text {anchor }}=3.000, \mathrm{M}_{\text {non-anchor }}=2.823, \mathrm{t}=1.455\right.$, $\mathrm{p}>0.05)$. In addition, we expected significant differences between upscale (downscale) anchor store image and downscale (upscale) nonanchor store image. A paired sample $t$-test shows that there are significant differences between upscale anchor store image and downscale non-anchor store image $\left(\mathrm{M}_{\text {anchor }}=4.316, \mathrm{M}_{\text {non-anchor }}=2.353, \mathrm{t}=\right.$
17.565, $\mathrm{p}<0.001)$ and between upscale anchor store image and downscale non-anchor store image $\left(\mathrm{M}_{\text {anchor }}=2.820, \mathrm{M}_{\text {non-anchor }}=\right.$ $3.945, \mathrm{t}=-8.470, \mathrm{p}<0.001)$. These tests show that anchor store image and non-anchor store image have been successfully manipulated.

\subsection{Hypothesis tests}

\subsubsection{The effect of image gap on spillover patronage}

The factorial variance analysis of the effect of anchor versus nonanchor store image on spillover patronage shows that the main effect of anchor store image $(\mathrm{F}(1,128)=4.646, \mathrm{p}<0.05)$ as well as the main effect of non-anchor store image $(F(1,128)=63.710, p<0.001)$ are significant. Also, the interaction effect between anchor store image and non-anchor store image is significant $(\mathrm{F}(1,128)=116.759, \mathrm{p}<0.001)$. That is to say, spillover patronage is affected not only by anchor store image, but also by non-anchor store image. Also, these image perceptions interact to create an additional effect. Fig. 2 shows that when anchor store image and non-anchor store image are at the same level, the extent of spillover patronage is relatively high. Spillover patronage is low when anchor store image and non-anchor store image are at different levels. That is to say, that the smaller the gap between the images of the anchor store versus the non-anchor store, the greater the extent of spillover patronage. This lends evidence for the support of $\mathrm{H} 1$.

Further regression analysis is used to test the effect of image gap on spillover patronage (see Table 4). F values of Model 1 and Model 3 are significant at 0.001 level, and Model 2 was significant at 0.10 level. The results of the regression analysis further support the hypothesis of the significant effect of image gap on spillover patronage $(\beta=-0.464, \mathrm{p}<$ $0.001)$. Moreover, anchor/non-anchor multiple self-congruity has a positive effect on the spillover patronage $(\beta=0.368, \mathrm{p}<0.001)$. This finding provides evidence that lends support for $\mathrm{H} 2$. We also hypothesized that image gap affects the formation of anchor/non-anchor multiple self-congruity. The results support $\mathrm{H} 3(\beta=-0.150, \mathrm{p}<0.10)$.

To further test the formation mechanisms of spillover patronage, we employed Process Procedure Model 4 (Version 3.5.3 for SPSS) to examine the mediating effect of multiple self-congruity on the association between image gap and spillover patronage (Hayes, 2018). The test confirms the significant negative direct effect of image gap on spillover patronage $(\mathrm{t}=-5.68, \mathrm{p}<0.001$, LLCI -0.621 ULCI -0.300 ), thus once more confirming $\mathrm{H} 1$. In addition, it confirms the direct effect of multiple self-congruity on spillover patronage $(t=5.117, p<0.001$, LLCI 0.257 ULCI 0.581), thus confirming H2. Hayes' procedure has also confirmed $H 3$, although the effect appears to be marginally significant $(t=-1.73$, $\mathrm{p}=0.853$, LLCI -0.291 ULCI -0.066). However, the assumption of mediation did not hold, since the indirect effect of image gap on spillover patronage was not significant $(b=-0.062$, se $=0.038$, BootLLCI

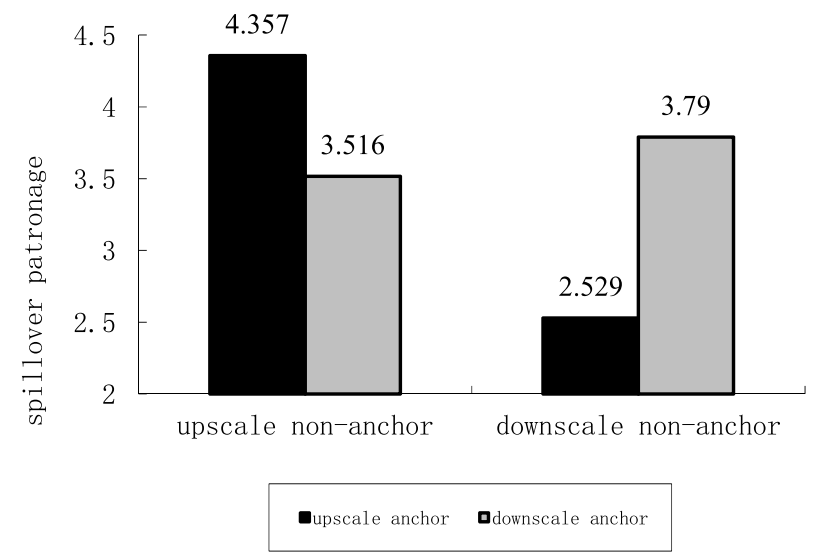

Fig. 2. The effect of store type on spillover patronage. 
Table 4

Regression analysis of image gap, multiple self-congruity and spillover patronage.

\begin{tabular}{|c|c|c|c|}
\hline \multirow[t]{3}{*}{ IV } & \multicolumn{3}{|l|}{ DV } \\
\hline & Model 1 & Model 2 & Model 3 \\
\hline & $\begin{array}{l}\text { Spillover } \\
\text { Patronage }\end{array}$ & $\begin{array}{l}\text { Multiple Self- } \\
\text { Congruity }\end{array}$ & $\begin{array}{l}\text { Spillover } \\
\text { Patronage }\end{array}$ \\
\hline $\begin{array}{l}\text { Image Gap } t- \\
\quad \text { value } \\
f^{2} \text { (effect size) }\end{array}$ & $\begin{array}{l}-0.464[-0.691, \\
-0.340](-5.977) \\
* * *\end{array}$ & $\begin{array}{l}-0.150[-0.292 \\
-0.002](-1.734) \\
+\end{array}$ & $\begin{array}{l}-0.409[-0.633, \\
-0.309](-5.687) \\
* * *\end{array}$ \\
\hline & 0.274 & 0.023 & 0.195 \\
\hline $\begin{array}{l}\text { Multiple Self- } \\
\text { Congruity } t \text { - } \\
\text { value }\end{array}$ & & & $\begin{array}{l}0.368[-0.633, \\
-0.309](5.117) \\
* * *\end{array}$ \\
\hline$f^{2}$ (effect size) & & & 0.153 \\
\hline $\mathrm{R}^{2}\left(\operatorname{Adj~} \mathrm{R}^{2}\right)$ & $0.216(0.210)$ & $0.023(0.015)$ & $0.348(0.338)$ \\
\hline $\mathrm{F}$ value & $35.723^{* * *}$ & $3.007^{+}$ & $34.413^{* * *}$ \\
\hline $\begin{array}{l}\text { Degrees of } \\
\text { Freedom }\end{array}$ & $1 / 130$ & $1 / 130$ & $2 / 129$ \\
\hline
\end{tabular}

Note: + indicates $\alpha<0.10 ; * * * \alpha<0.00$; the intervals within brackets are bootstrap results based on 5000 bootstrap samples.

\section{-0.1221 BootULCI 0.004).}

\subsubsection{Moderating effect of purchase likelihood in the anchor store}

We run multivariate regression analysis to test the moderating effect of purchase incidence in the anchor store. Table 5 presents the results. Model 4 tests the effect of anchor/non-anchor multiple self-congruity as well as that of purchase in anchor store on spillover patronage. Building on Model 4, Model 5 includes the interaction term: [multiple selfcongruity $\mathrm{x}$ purchase in anchor store]. In order to reduce potential multiple collinearity among the interaction term and the independent variable, the independent variable and the interaction factor are standardized. All models prove to be significant at 0.001 level. It can be seen in Table 5 that the coefficient of the interaction term is not significant (see Table 5). It shows that purchase in the anchor store does not moderate the effect of multiple self-congruity on spillover patronage. Based on this finding, we reject $\mathrm{H} 4$. We also perform Hayes' process procedure to test the moderating effect. This test confirms our prior finding that the moderating effect of purchase in anchor store on the multiple self-congruity/spillover patronage relationship is not significant $(\mathrm{t}=0.5945, \mathrm{p}>0.10$, LLCI -0.126 ULCI 0.234$)$.

Model 6 examines the effect of store image gap and that of purchase in anchor store on spillover patronage. Model 7 builds further on Model 6 by adding the following interaction term: [image gap $\mathrm{x}$ purchase in anchor store]. We standardize the variables to minimize potential multicollinearity. We find Models 6 and 7 to be significant at 0.001 level.
The effect of the interaction term is also significant at 0.01 level (Table 5). These results show that purchase in anchor store moderates the effect of image gap on spillover patronage. H5 is supported. We also perform Hayes' process procedure to test this hypothesized moderation effect. This test confirms our prior finding that the moderating effect of purchase in anchor store on the image gap/spillover patronage relationship is significant $(\mathrm{t}=-0.279, \mathrm{p}<0.01$, LLCI -0.454 ULCI -0.104). The moderating effect is negative. This means that anchor store purchase amplifies the negative effect of image gap on spillover patronage. While the conditional effect in the non-purchase condition is not significant $(\mathrm{t}=-0.987, \mathrm{p}>0.10$, LLCI -0.434 ULCI 0.145$)$, it becomes significant in the purchase condition $(\mathrm{t}=-6.831, \mathrm{p}<0.001$, LLCI -0.918 ULCI -0.506).

Fig. 3a visually indicates that, within the range of the independent variables, there is no intersection between two spillover patronage lines under the different conditions: purchase in anchor store versus nonpurchase in anchor store (see Fig. 3a). Hence, it can be seen visually that purchase in anchor store does not moderate the effect of multiple self-congruity on spillover patronage. When shoppers experience high self-image congruence, they are likely to additionally patronize nonanchor stores whether they buy in the anchor store or not.

The visual examination of the moderating effect of purchase likelihood in the anchor store (Table $3 b$ ) indicates, that within the range of the independent variables, an intersection exists between two spillover patronage lines arising from the different conditions: purchase in anchor store and non-purchase in anchor store (see Fig. 3b). Purchase in anchor store moderates the effect of image gap on spillover patronage via amplifying the negative effect. In other words, when shoppers are likely to engage in purchase in the anchor store, the smaller image gap definitely leads to a greater extent of spillover patronage. When shoppers are not likely to engage in purchase in the anchor store, the negative effect of image gap on spillover patronage dissipates.

\section{Research conclusions}

\subsection{Discussion}

Previous research attempted to explain spillover shopping through having recourse to spatial, temporal, and retail type based variation in shop-level variables such as traffic and sales (for a brief summary refer to Chung et al., 2021). In contrast, this research delves into variation due to customers' perceptions, thus attempting to better explain the cognitive formation mechanisms of spillover patronage that is activated within a shopping mall. Based on the compiled data obtained through shopping-mall intercepts and laboratory experiments, it is found that perceived image gap is negatively associated with spillover patronage, whereas multiple self-congruity is positively associated with the same

Table 5

Testing the moderating effect of purchase incidence in anchor store.

\begin{tabular}{|c|c|c|c|c|c|}
\hline & Testing H4 & & & Testing H5 & \\
\hline Variable & Model 4 & Model 5 & variable & Model 6 & Model 7 \\
\hline Multiple self-congruity $f^{2}$ (effect size) & $\begin{array}{l}0.476^{* * *}[0.332, \\
0.748] \\
0.267\end{array}$ & $\begin{array}{l}0.483 * * *[0.342 \\
0.753] \\
0.270\end{array}$ & $\begin{array}{l}\text { Image gap } \\
f^{2} \text { (effect size) }\end{array}$ & $\begin{array}{l}-0.463^{* * *}[-0.693, \\
-0.341] \\
0.273\end{array}$ & $\begin{array}{l}-0.430 * * *[-0.649, \\
-0.300] \\
0.222\end{array}$ \\
\hline Purchase in anchor store $f^{2}$ (effect size) & $\begin{array}{l}-0.177 *[-0.585 \\
-0.050] \\
0.030\end{array}$ & $\begin{array}{l}-0.174 *[-0.568 \\
-0.040]< \\
0.029\end{array}$ & $\begin{array}{l}\text { Purchase in anchor store } f^{2} \\
\text { (effect size) }\end{array}$ & $\begin{array}{l}-0.032[-0.335, \\
0.215] \\
0.001\end{array}$ & $\begin{array}{l}-0.038[-0.339 \\
0.205] \\
0.001\end{array}$ \\
\hline $\begin{array}{l}\text { Multiple self-congruity x Purchase in anchor } \\
\text { store } f^{2} \text { (effect size) }\end{array}$ & & $\begin{array}{l}0.047[-0.118,0.202] \\
0.002\end{array}$ & $\begin{array}{l}\text { Image gap x Purchase in } \\
\text { anchor store } \\
f^{2} \text { (effect size) }\end{array}$ & & $\begin{array}{l}-0.240 * *[-0.368 \\
-0.075] \\
0.061\end{array}$ \\
\hline $\begin{array}{l}\mathrm{R}^{2}\left(\text { Adj } \mathrm{R}^{2}\right) \\
\Delta \mathrm{R}^{2}\end{array}$ & $0.214(0.201)$ & $\begin{array}{l}0.216(0.197) \\
0.002\end{array}$ & $\begin{array}{l}\mathrm{R}^{2}\left(\operatorname{Adj} \mathrm{R}^{2}\right) \\
\Delta \mathrm{R}^{2}\end{array}$ & $0.217(0.204)$ & $\begin{array}{l}0.273(0.256) \\
0.057\end{array}$ \\
\hline F value & $17.524 * * *$ & $11.742^{* * *}$ & F value & 17.832 & 16.033 \\
\hline Degrees of Freedom & $2 / 129$ & $3 / 128$ & Degrees of Freedom & $2 / 129$ & $3 / 128$ \\
\hline
\end{tabular}

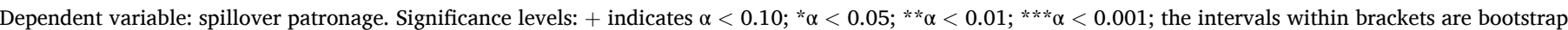
results based on 5000 bootstrap samples. 

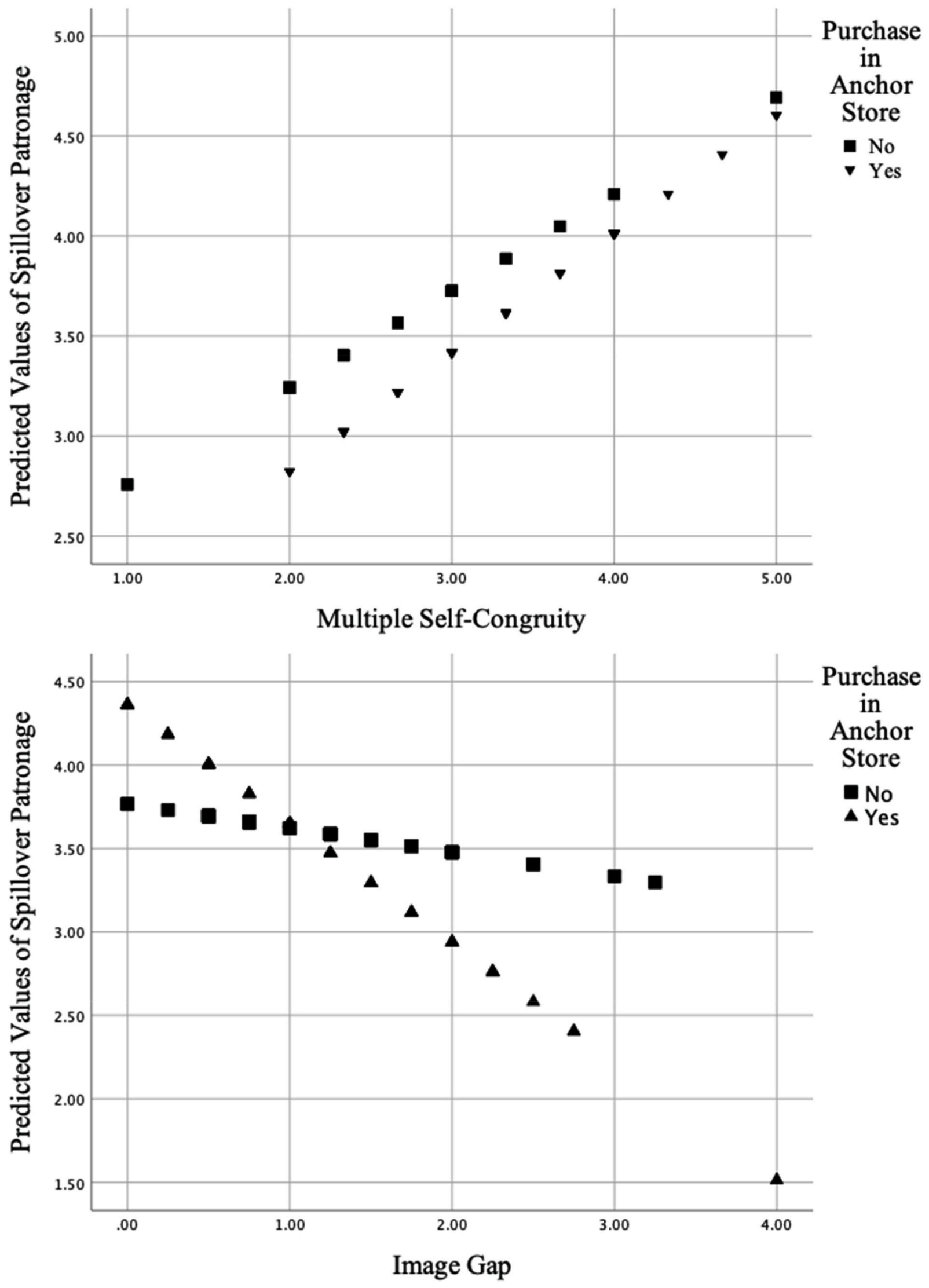

Fig. 3. a. Interaction effect due to purchase incidence in anchor store. Fig. 3b. Interaction effect due to purchase incidence in anchor store. 
variable. These findings are important, because in contrast to the previous research indicating a negative spillover effect between same-market retailers, i.e. stores selling identical categories of products (Arcidiacono et al., 2019; Artz and Stone, 2006; Stone, 1997; Daunfeldt et al., 2019), the current research shows that this effect may not always be the case at the individual level. Non-significant perceived image gap as well as multiple self-congruity increases the likelihood of spillover shopping. The more similar the images of non-anchor and anchor stores, irrespective of them being the same-market retailers, it will be easier for non-anchor stores to tap into original customer traffic generated by the anchor store. Moreover, the current research finds that irrespective of the stores being upscale or downscale, if the image of the non-anchor store is similar to that of the anchor store, the non-anchor store will continue benefiting from customers spilling over from the anchor store. While the past research highlighted retailer differences on the basis of product complementarity, substitutability, spatial distance (Chung et al., 2021; Haltiwanger et al., 2010), no research linked spillover shopping, specifically, spillover patronage to consumers' image congruence perceptions. It is generally true that complimentary services such as bars, restaurants, eateries, and other local service providers thrive due to spillover shopping, while substitute retailers suffer (Artz and Stone, 2006; Haltiwanger et al., 2010). However, the current research shows that substitute retailers may also benefit from spillover if they can attain better multiple image congruence with big-box retailer customers. Managers in shopping malls should consider ways to enhance not only the anchor store's image, but also respective non-anchor store images. Moreover, this research finds the act of purchase as a boundary condition of the image gap - spillover patronage relationship. The significance of purchase while browsing has been recognized in past research (Reynolds et al., 2012), although it has not been linked to spillover shopping. Our findings indicate that non-purchase dissipates image gaps negative effect on spillover shopping, while purchase amplifies this effect.

\subsection{Research contributions and managerial implications}

The current research theoretically recasts spillover shopping from the anchor store customer's experiential-cognitive perspective. Spillover shopping is re-labelled as spillover patronage and it is explained through the causal path of store image gap $\rightarrow$ multiple self-image congruence $\rightarrow$ spillover patronage. This study links multi-store patronage from the perspective of image gap and determines relevant bpundary conditions and formation mechanisms of spillover patronage. Second, the existing studies confine self-image congruence only to the shopper's relationship with an individual store. This study proposes multi-store self-image congruence which extends the research and application scope of selfimage congruence theory.

This study has the following managerial implications. The managers of a shopping mall can diagnose image gap between anchor stores and non-anchor stores. Enhancing and supporting spillover shopping through effective image management would make the whole shopping mall attain a synergy effect, and thus enhance the economy of agglomeration. Small non-anchor stores in general shopping malls tend to bear relatively high rental costs while enjoying limited attractiveness. If they fail to attract more customers, this may cause difficulties in operation for both the shopping mall management and these stores. Small non-anchor stores can take various initiatives to narrow the image gap with the anchor stores and attract more of spillover customers. Non-anchor stores can also take the initiative to understand the characteristics of big-box retailer customer groups, effectively locate these micro-segments, and carry out targeted marketing strategies to attract these potential target groups into their store.

\subsection{Limitations and future research}

This study focuses on self-image congruence to explain the spillover patronage effect of an anchor store on non-anchor stores in a shopping mall. It should be noted that consumers' self-image can be multidimensional. Different dimensions of self-image have different effects on consumer attitudes and behaviors. So, what is the effect of the consumer's ideal self-image congruence and social self-image congruence on spillover patronage flowing from anchor stores to non-anchor stores? Can these factors also explain spillover patronage? Further research could test the role of these concepts. Moreover, this study inherits a viewpoint of retail demand externality theory, that is, anchor stores in a shopping mall representing the main force of attracting consumers to the shopping mall, because of its large area, abundant assortments, and retail power. But the opposite could be true as well: non-anchor stores may attract customers to anchor stores. Specifically, some very distinctive, unique, and niche stores could pull customers to shopping centers. Hence, in-depth research on the direction of spillover patronage needs to be conducted in future. Furthermore, this study uses the data obtained by a field survey and experiments to test the hypotheses. In future, RFID technology can be used to insert chips into shopping carts or membership cards, or a mobile app can be used to obtain the real data of shoppers' movement paths to detect spillover patronage. In addition, social network methods can be used to analyze these shoppers' interaction behavior.

\section{References}

Ahluwalia, R., Unnava, H.R., Burnkrant, R.E., 2001. The moderating role of commitment on the spillover effect of marketing communications[J]. J. Market. Res. 38 (4), 458-470.

Ailawadi, K.L., Zhang, J., Krishna, A., Kruger, M., 2010. When Wal-Mart enters: how incumbent retailers react and how this affects their sales outcomes. J. Market. Res. 47, 577-593.

Arcidiacono, P., Ellickson, P.B., Mela, C.F., Singleton, J.D., 2019. The Competitive Effects of Entry: Evidence from Supercenter Expansion. American Economic Journal: Applied Economics, forthcoming.

Arentze, T.A., Oppewal, H., Timmermans, H.J.P., 2005. A multipurpose shopping trip model to assess retail agglomeration effects[J]. J. Market. Res. 42 (1), 109-115.

Artz, G.M., Stone, K.E., 2006. Analyzing the impact of Wal-Mart supercenters on local food store sales. Am. J. Agric. Econ. 88, 1296-1303.

Bagozzi, R.P., Yi, Y., 1988. On the evaluation of structural equation models[J]. J. Acad. Market. Sci. 16 (1), 74-94.

Baker, J., Grewal, D., Parasuraman, A., 1994. The influence of store environment on quality inferences and store image[J]. J. Acad. Market. Sci. 22 (4), 328-339.

Balachander, S., Ghose, S., 2003. Reciprocal spillover effects: a strategic benefit of brand extensions[J]. J. Market. 67 (1), 4-13.

Basker, E., 2005. Job creation or destruction? Labor market effects of Wal-Mart expansion. Rev. Econ. Stat. 87, 174-183.

Basker, E., 2007. The causes and consequences of Wal-Mart's growth. Journal of Economic Perspectives 21 (3), 177-198.

Belwal, R., Belwal, S., 2017. Factors affecting store image and the choice of hypermarkets in Oman[J]. Int. J. Retail Distrib. Manag. 45 (6), 587-607.

Burlison, J., Oe, H., 2018. A discussion framework of store image and patronage: a literature review[J]. Int. J. Retail Distrib. Manag. 46 (7), 705-724.

Chebat, J.C., Sirgy, M.J., Grzeskowiak, S., 2010. How can shopping mall management best capture mall image?[J]. J. Bus. Res. 63 (7), 735-740.

Chebat, J.C., Sirgy, M.J., St-James, V., 2006. Upscale image transfer from malls to stores: a self-image congruence explanation[J]. J. Bus. Res. 59 (12), 1288-1296.

Chung, H., Ahn, D.Y., Ahn, S., 2021. Spillover effects of a mega shopping complex on preexisting, small retail shops over space, over time and across retail types. J. Retailing Consum. Serv. 102518.

Chung, W., Kalnins, A., 2001. Agglomeration effects and performance: a test of the Texas lodging industry. Strat. Manag. J. 22, 969-988.

Collins, M.A., Loftus, F.E., 1975. A spreading-activation theory of semantic processing [J]. Psychol. Rev. 82 (6), 407-428.

Conejo, F., Wooliscroft, B., 2015. Brands defined as semiotic marketing systems. J. Macromarketing 35 (3), 287-301.

Dahlén, M., Lange, F., 2006. A disaster is contagious: how a brand in crisis affects other brands [J]. J. Advert. Res. 46 (4), 388-397.

Daunfeldt, S.O., Mihaescu, O., Nilsson, H., Rudholm, N., 2019. Spillover effects when IKEA enters: do incumbent retailers win or lose? Pap. Reg. Sci. 98 (6), 2295-2313.

Daunfeldt, S.O., Mihaescu, O., Nilsson, H., Rudholm, N., 2019. Spillover effects when IKEA enters: Do incumbent retailers win or lose? Papers in Regional Science 98 (6), 2295-2313.

De Bruyn, A., Prokopec, S., 2017. Assimilation-contrast theory in action: operationalization and managerial impact in a fundraising context. Int. J. Res. Market. 34 (2), 367-381.

Diallo, M.F., Cliquet, G., 2016. Store image perceptions and customer knowledge cues in emerging markets: a cross-country investigation in Brazil and Vietnam[J]. Int. J. Retail Distrib. Manag. 44 (12), 1182-1205. 
Dolich, I.J., 1969. Congruence relationships between self-images and product brands[J]. J. Market. Res. 6 (1), 80-84.

Erdem, T., Sun, B., 2002. An empirical investigation of the spillover effects of advertising and sales promotions in umbrella branding[J]. J. Market. Res. 39 (4), 408-420.

Feldman, J.M., Lynch Jr., J.G., 1988. Self-generated validity and other effects of measurement on belief, attitude, intention, and behavior [J]. J. Appl. Psychol. 73 (3), 421-435.

Gatzlaff, D., Sirmans, S., Diskin, B., 1994. The effect of anchor tenant loss on shopping center rents[J]. J. R. Estate Res. 9 (1), 99-110.

Greenstone, M., Hornbeck, R., Moretti, E., 2010. Identifying agglomeration spillovers: evidence from winners and losers of large plant openings. J. Polit. Econ. 118, $536-598$.

Ha, S., Im, H., 2012. Identifying the role of self-congruence on shopping behavior in the context of US shopping malls[J]. Cloth. Text. Res. J. 30 (2), 87-101.

Haltiwanger, J.C., Jarmin, R.R., Krizan, C.J., 2010. Mom-and-pop meet big-box: complements or substitutes? J. Urban Econ. 67, 116-134.

Hayes, A.F., 2018. Introduction to mediation, moderation, and conditional process analysis: A regression-based approach, 2nd ed. Guilford publications, New York.

Hosany, S., Martin, D., 2012. Self-image congruence in consumer behavior[J]. J. Bus. Res. 65 (5), 685-691.

Hu, L., Bentler, P.M., 1999. Cutoff criteria for fit indexes in covariance structure analysis: conventional criteria versus new alternatives. SEM 6 (1), 1-55.

Janakiraman, R., Sismeiro, C., Dutta, S., 2009. Perception spillovers across competing brands: a disaggregate model of how and when [J]. J. Market. Res. 46 (4), 467-481.

John, D.R., Loken, B., Joiner, C., 1998. The negative impact of extensions: can flagship products be diluted? J. Market. 62 (Jan), 19-32.

Kadirov, D., Varey, R.J., 2011. Symbolism in marketing systems. J. Macromarketing 31 (2), 160-171.

Lei, J., Dawar, N., Lemmink, J., 2008. Negative spillover in brand portfolios: exploring the antecedents of asymmetric effects [J]. J. Market. 72 (3), 111-123.

Martineau, P., 1958. The personality of the retail store[J]. Harv. Bus. Rev. 36 (Jan), 47-55.

Merriman, D., Persky, J., Davis, J., Baiman, R., 2012. The impact of an urban WalMart store on area businesses: the Chicago case. Econ. Dev. Q. 26 (4), 321-333.

Nevin, J.R., Houston, H.J., 1980. Image as a component of intra-urban shopping areas [J]. J. Retailing 56 (1), 77-93.

Noble, S.M., Griffith, D.A., Adjei, M.T., 2006. Drivers of local merchant loyalty: understanding the influence of gender and shopping motives. J. Retailing 82 (3), 177-188.

Onkvisit, S., Shaw, J., 1987. Self-concept and image congruence: some research and managerial implications [J]. J. Consum. Market. 4 (1), 13-23.

Padela, S.M.F., Wooliscroft, B., Ganglmair-Wooliscroft, A., 2020. Brand externalities: a taxonomy. J. Macromarketing, 0276146720961462.

Pan, Y., Zinkhan, G.M., 2006. Determinants of retail patronage: a meta-analytical perspective[J]. J. Retailing 82 (3), 229-243.

Paruchuri, S., Baum, J.A., Potere, D., 2009. The Wal-Mart effect: wave of destruction or creative destruction? Econ. Geogr. 85 (2), 209-236.

Reilly, R.J., Hoffer, G.E., 1983. Will retarding the information flow on automobile recalls affect consumer demand? [J]. Econ. Inq. 21 (6), 444-447.

Reynolds, K.E., Jones, M.A., et al., 2012. An investigation of retail outcomes comparing two types of browsers[J]. J. Bus. Res. 65 (8), 1090-1095.
Roehm, M.L., Tybout, A.M., 2006. When will a brand scandal spill over, and how should competitors respond? [J]. J. Market. Res. 43 (3), 366-373.

Roy, S., Ghosh, L., 2013. Understanding apparel store image: a scale development approach[J]. J. Serv. Res. 13 (2), 53-70.

Shoag, D., Veuger, S., 2018. Shops and the city: Evidence on local externalities and local government policy from big-box bankruptcies. Review of Economics and Statistics 100 (3), 440-453.

Sirgy, M.J., 1982. Self-concept in consumer behavior: a critical review[J]. J. Consum. Res. 9 (3), 287-300.

Sirgy, M.J., Grewal, D., Mangleburg, T.F., et al., 1997. Assessing the predictive validity of two methods of measuring self-image congruence [J]. J. Acad. Market. Sci. 25 (3), 229-241.

Sobel, R.S., Dean, A.M., 2008. Has Wal-Mart buried mom-and-pop? The impact of WalMart on self-employment and small establishments in the United States. Econ. Enquiry 46, 676-695.

Stone, K.E., 1997. Impact of the Wal-Mart phenomenon on rural communities. In: Increasing Understanding of Public Problems and Policies, pp. 189-200.

Sung, E., Huddleston, P., 2018. Department vs discount retail store patronage: effects of self-image congruence[J]. J. Consum. Market. 35 (1), 64-78.

Tamura Masanori, 2014. Location innovation [M].Translated by Wu Xiaoding et al. Science Press, Beijing.

Teller, C., 2012. Elms J. R. Urban place marketing and retail agglomeration customers [J]. J. Market. Manag. 28 (5-6), 546-567.

Teller, C., Schnedlitz, P., 2012. Drivers of agglomeration effects in retailing: the shopping mall tenant's perspective[J]. J. Market. Manag. 28 (9-10), 1043-1061.

Teller, C., Thomson, J.A., 2012. Gender differences of shoppers in the marketing and management of retail agglomerations[J]. Serv. Ind. J. 32 (6), 961-980.

Vogel, E.A., Rose, J.P., Aspiras, O.G., Edmonds, K.A., Gallinari, E.F., 2020. Comparing comparisons: assimilation and contrast processes and outcomes following social and temporal comparison. Self Ident. 19 (6), 629-649.

Wang, R., Zhang, C.Y., 2012. Research on retail agglomeration economy from the perspective of retail demand externalities theory [J]. J. Northeast Normal Univ. 260 (6), 251-253.

Wang, X.Y., 2012. Review and Prospect of spillover effects of product crisis on crisis brand competitors [J]. Foreign Econ. Manag. 34 (2), 58-64.

Wang, Z.J., Liang, J.P., Yu, H.Y., 2012. Spillover effect of customer experience: the effect of information clues and view of behavioral agent[J]. Chin. Manag. Stud. 7 (3), 68-85.

Wei, S., Hou, M., 2016. The theoretical dilemma of retail patronage research from the perspective of retail demand externalities [J]. J. Comm. Econ. (11), 5-8.

Wei, S., Wu, X.D., 2013. An exploratory study on the concept and measurement of store identity [J]. J. Bus. Econ. 257 (3), 73-80.

Westbrook, R.A., Black, W.C., 1985. A motivation-based shopper typology. J. Retailing 61 (1), 78-103.

Wolter, J.S., Cronin, J.J., 2016. Re-conceptualizing cognitive and affective customer-company identification: the role of self-motives and different customerbased outcomes. J. Acad. Market. Sci. 44 (3), 397-413.

Wolter, J.S., Bock, D., Smith, J.S., Cronin Jr., J.J., 2017. Creating ultimate customer loyalty through loyalty conviction and customer-company identification. J. Retailing 93 (4), 458-476. 